\title{
Awareness of and receiving social protection measures during COVID-19 lockdown in Bihar, India
}

UNICEF

Population Council Institute

Follow this and additional works at: https://knowledgecommons.popcouncil.org/departments_sbsr-pgy

Part of the Demography, Population, and Ecology Commons, International Public Health Commons, and the Public Health Education and Promotion Commons How does access to this work benefit you? Let us know!

\section{Recommended Citation}

UNICEF and Population Council Institute. 2020. "Awareness of and receiving social protection measures during COVID-19 lockdown in Bihar, India," COVID-19 Research Results Brief \#3. New Delhi: UNICEF and Population Council Institute. 


AWARENESS OF AND
RECEIVING SOCIAL
PROTECTION
MEASURES DURING
COVID-19
LOCKDOWN IN
BIHAR, INDIA

Majority of respondents (64\%) reported a family member losing their job/income earning opportunity and lacking resources to survive for long.

Awareness of social protection schemes was high (88\%).

$68 \%$ households reported having ration cards - $95 \%$ out of those reported having received ration in the month preceding the survey, 40 percent ration card holders found the quantities of ration insufficient.

$\mathbf{5 5 \%}$ received cash benefits from various social protection schemes. Identification of households in need of social protection and streamlining the disbursement of these benefits are also required. Given the pervasive job difficulties and limited resources households have had to survive, increasing the amount of cash transfers and creating local job opportunities need to be considered.

\section{BACKGROUND}

$\square$ Economic hardships caused by the nationwide lockdown to prevent the spread of COVID-19 are reported across the country. Social protection measures have been announced by the state and central governments to ease these hardships.

$\square$ The key objectives of this research brief are to examine the awareness and the social protection measures received during COVID-19 lockdown and the socio-economic differentials in receiving these measures.

\section{METHODS}

$\square$ The sample households for the KAP surveys were drawn from an existing state-representative cohort study of adolescents and young adults under project UDAYA (www.projectudaya.in) in Bihar. However, it is noted that respondents who participated in the COVID-19 KAP surveys were better educated, wealthier and less likely to have belonged to disadvantaged castes and tribes (SC/ST), compared with those who did not. There were no differences in terms of rural-urban or religious distributions.

$\square 242$ men and 552 women were interviewed between May 1322, 2020. (See Table below for the profile of study participants).

$\square$ Data was also drawn from the survey of SHG leaders ( $N=179$ ); more details can be found in the brief entitled Self help group: A potential pivot of Bihar's response to COVID-19.

\section{STUDY PARTICIPANTS' PROFILE}

\begin{tabular}{|c|c|c|c|}
\hline Characteristics & $\begin{array}{l}\text { Male } \\
(\mathrm{N}=242)\end{array}$ & $\begin{array}{l}\text { Female } \\
(\mathrm{N}=552)\end{array}$ & $\begin{array}{c}\text { Total } \\
(\mathrm{N}=794)\end{array}$ \\
\hline 18-24-year-olds $(\%)^{1}$ & 80 & $89 * * *$ & 86 \\
\hline Mean years of schooling & 11 & $10 * * *$ & 10 \\
\hline \% Rural & 61 & $62 * *$ & 62 \\
\hline$\%$ Hindu & 84 & 86 & 86 \\
\hline \multicolumn{4}{|l|}{ Caste (\%) } \\
\hline $\mathrm{SC} / \mathrm{ST}$ & 16 & 17 & 16 \\
\hline Other backward caste & 63 & 64 & 64 \\
\hline General & 21 & 19 & 20 \\
\hline \multicolumn{4}{|l|}{$\begin{array}{l}\text { Wealth index (quintiles as of } \\
\text { UDAYA 2015-16 survey) }\end{array}$} \\
\hline Bottom two quintiles (poor) & 8 & 16 & 14 \\
\hline Medium & 15 & 13 & 14 \\
\hline Top two quintiles (rich) & 77 & 71 & 72 \\
\hline Migrant households (\%) & 36 & 32 & 33 \\
\hline $\begin{array}{l}\text { Households with at least one } \\
\text { school-going child aged 6-14 }\end{array}$ & 41 & 36 & 38 \\
\hline $\begin{array}{l}\text { Households with at least one } \\
\text { school-going child attending a } \\
\text { government school }\end{array}$ & 24 & 19 & 20 \\
\hline $\begin{array}{l}\text { Households with a pregnant or } \\
\text { lactating woman or a child aged } \\
6-72 \text { months }\end{array}$ & 29 & $58 * * *$ & 49 \\
\hline Households holding a ration card & 72 & 67 & 68 \\
\hline
\end{tabular}

\section{ECONOMIC SHOCKS DURING LOCKDOWN}

UDAYA cohort households $(\mathrm{N}=794)$

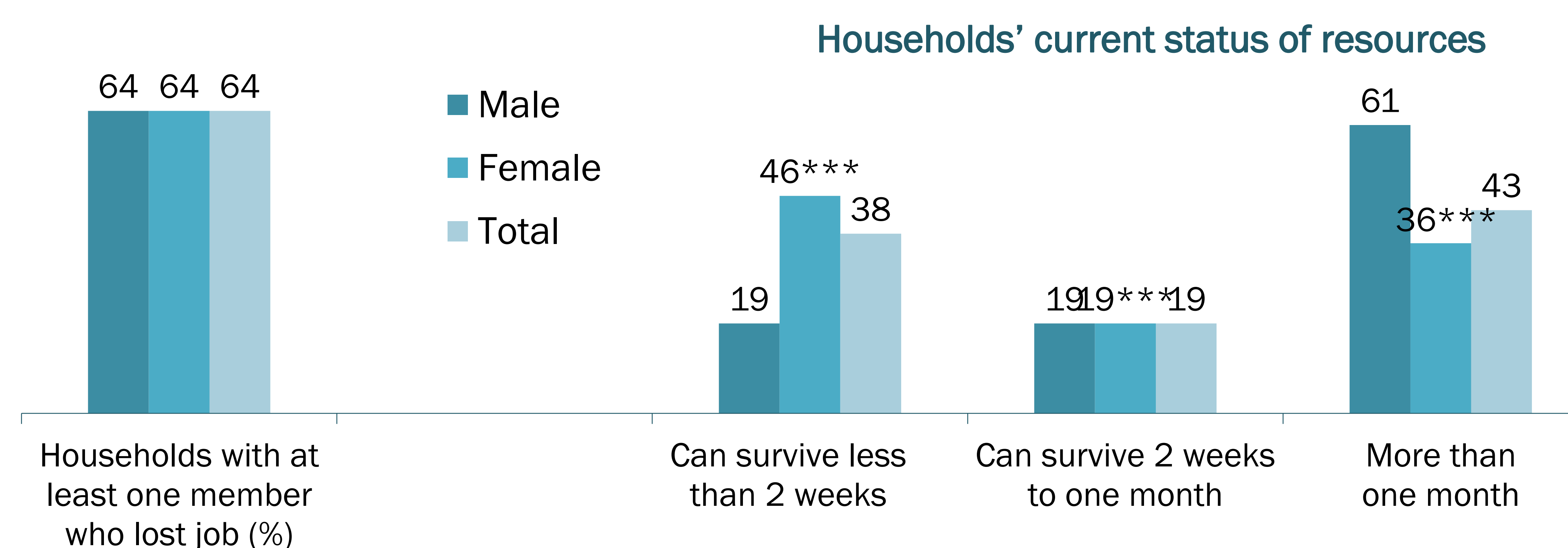

UDAYA cohort migrant households $(\mathrm{N}=264)$

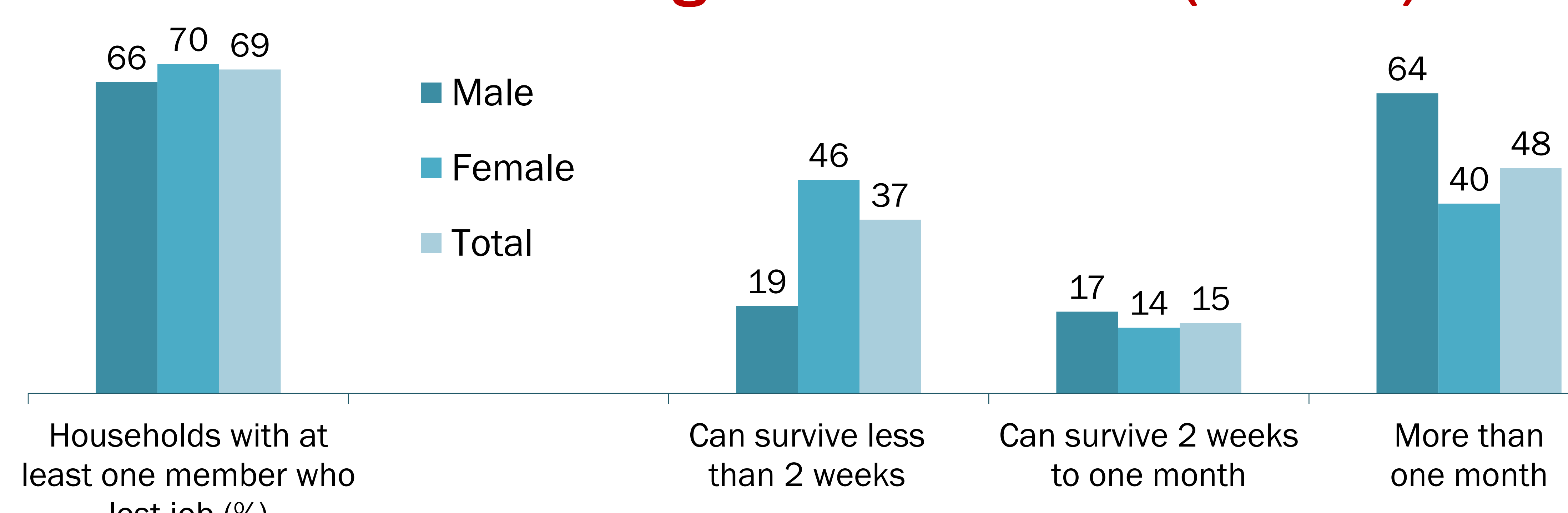
lost job (\%)

SHG leaders $(\mathrm{N}=179)$

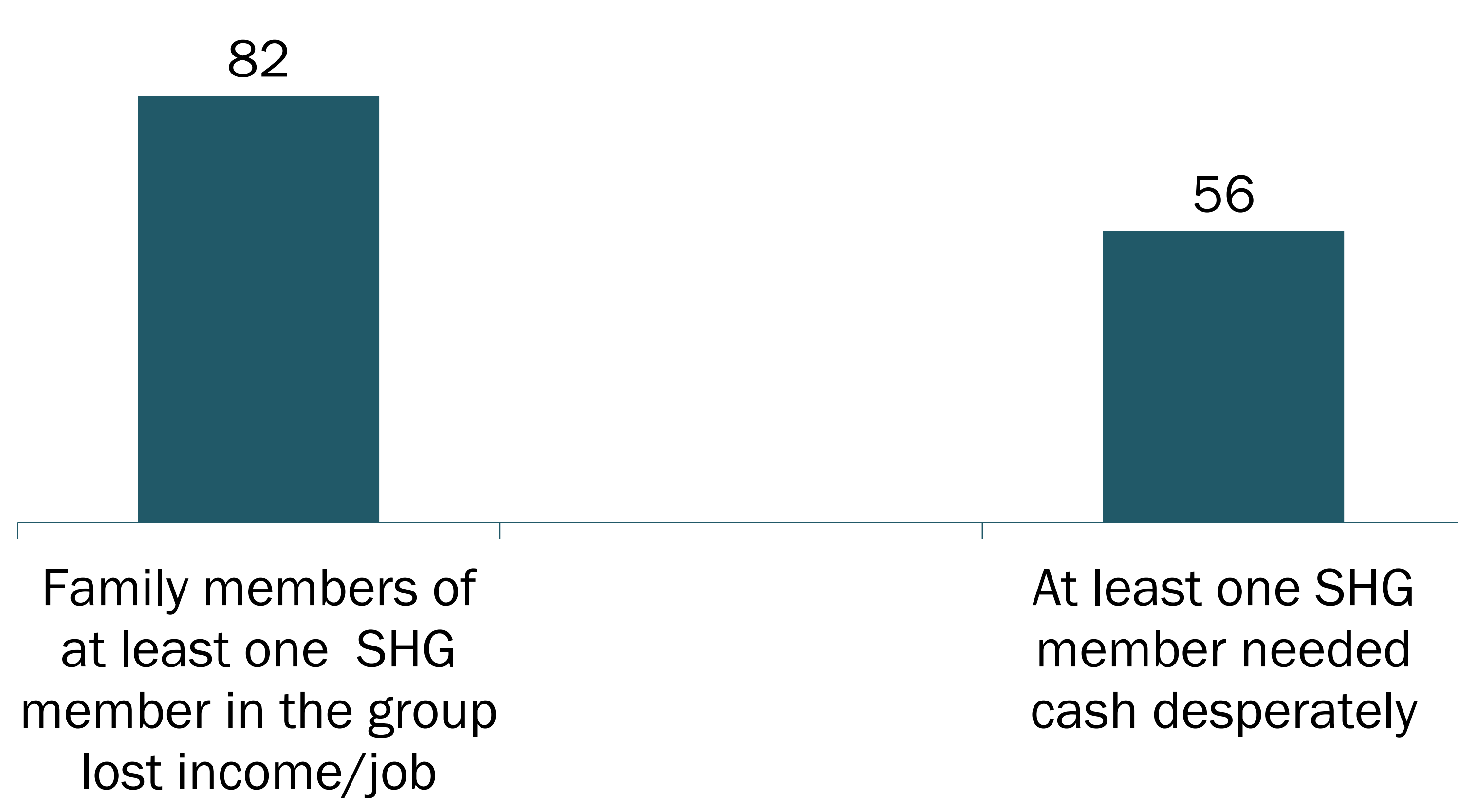

$\square$ Majority of participants in the household survey and the survey of SHG leaders reported loss of job/income earning opportunities and limited resources to survive.

\section{AWARENESS OF SOCIAL PROTECTION SCHEMES ${ }^{\circledR}$}

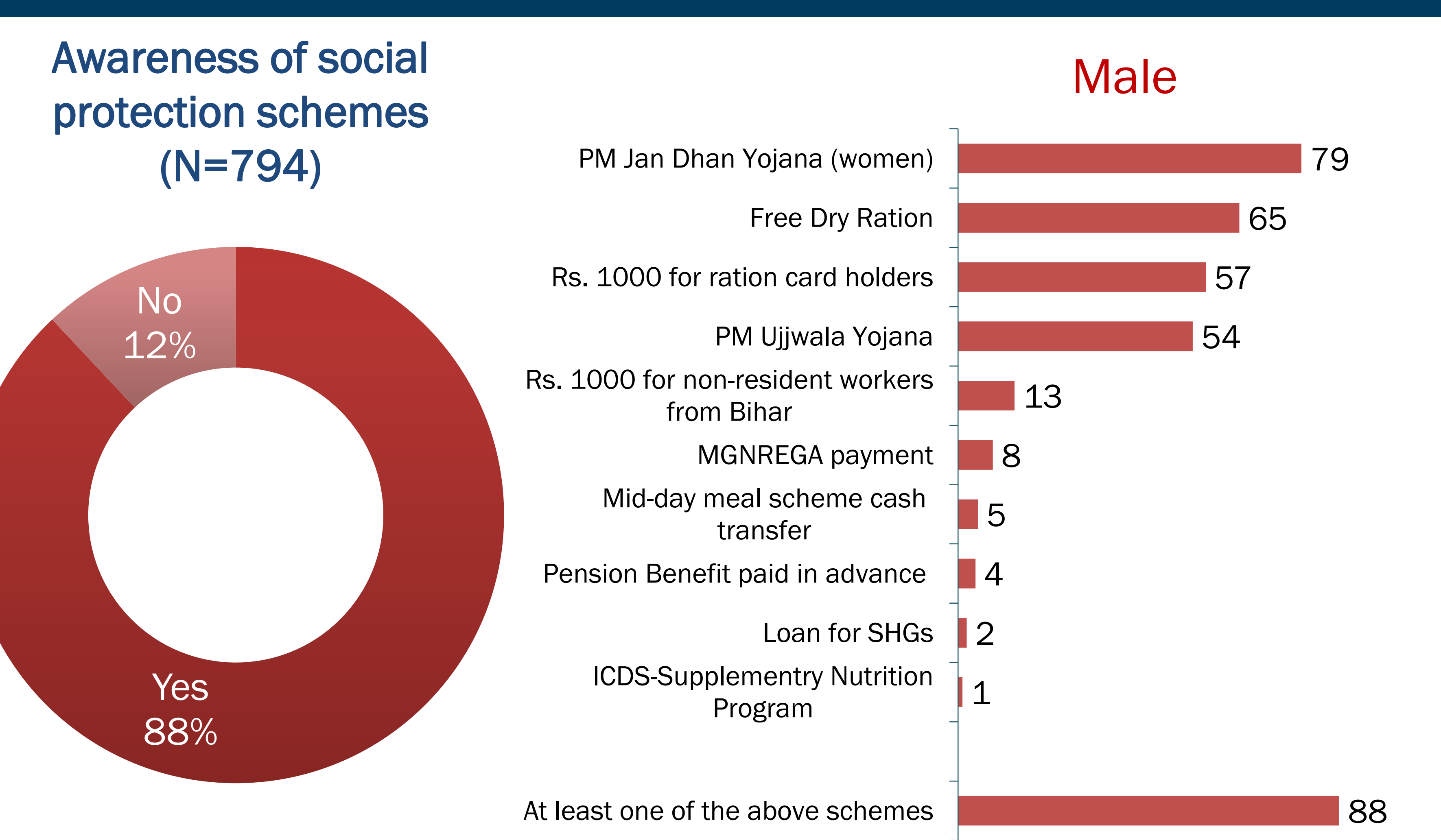

Female

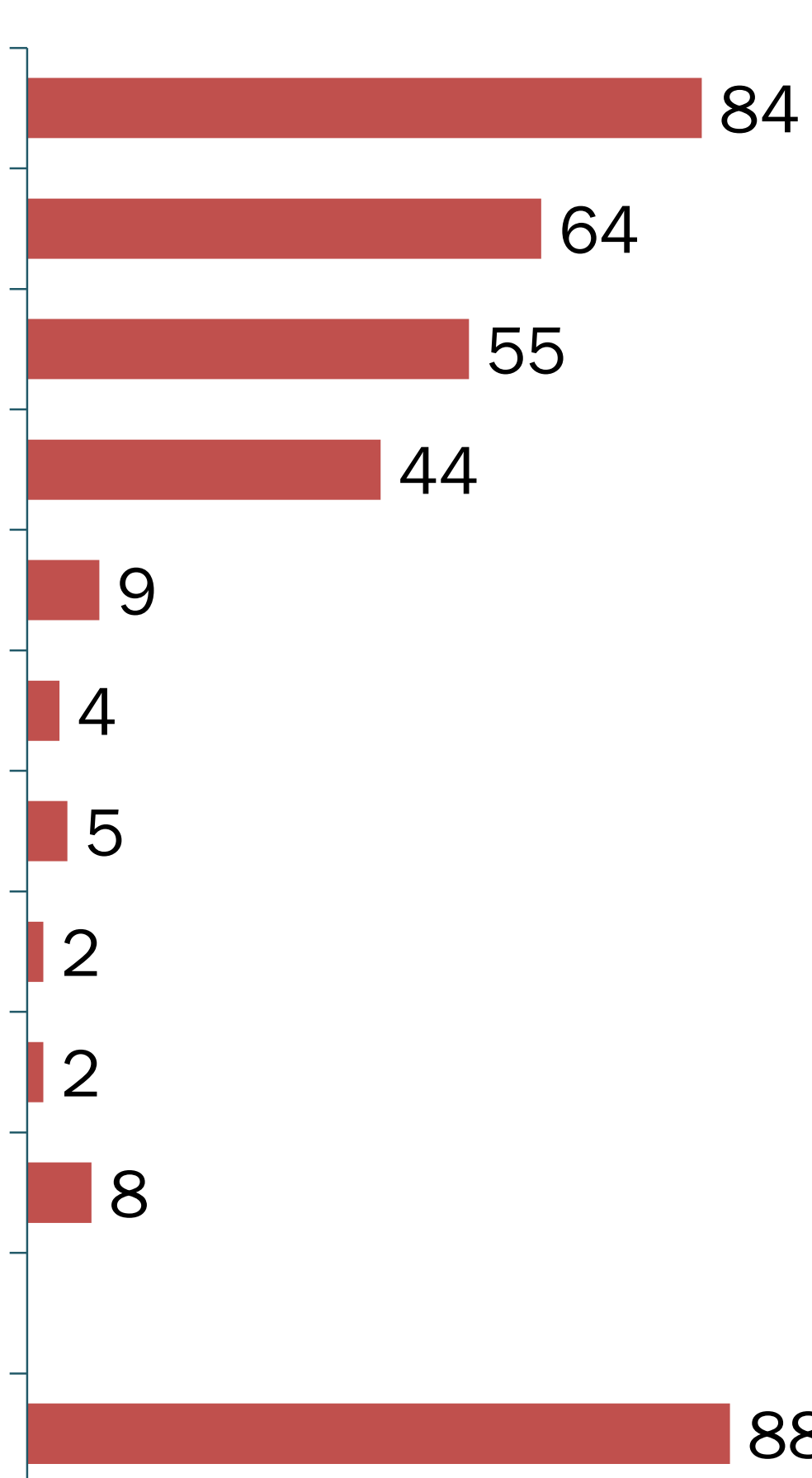

Note: ${ }^{\circledR}$ Based on answers given spontaneously in response to a single question about the awareness of social protection schemes, multiple responses possible.

$\square$ Almost 9 out of 10 participants, regardless of sex, were aware of at least one social protection measure.

$\square$ Most widely known measure was PM Jan Dhan Yojna (83\% listed it spontaneously), followed by free dry ration (65\%).

$\square$ Most participants heard about these measures either from television (64\%) or social media (51\%). 
